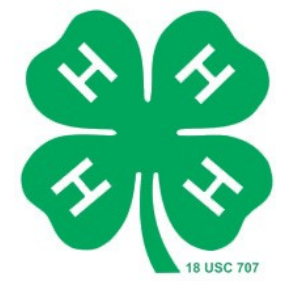

\title{
Understanding 4-H Youth Development Delivery ${ }^{1}$
}

Marilyn N. Norman and Joy C. Jordan ${ }^{2}$

\section{4-H Delivery Methods}

4-H uses a variety of methods and locations for reaching youth with opportunities that help them grow and develop in positive ways including:

- Organized Clubs

- School Enrichment Programs

- Residential/Overnight Camps

- After-school Programs

- Special Interest Classes/Clinics or Day Camps

- Individual Study/ Internet

In Florida, the term 4-H member and 4-H participant are used synonymously when youth engage in a minimum of six (6) hours of educational learning experiences, regardless of delivery method. This may include :

- a youth enrolled in an organized 4-H club;

- a youth enrolled in a 4-H after-school program;

- a youth enrolled in a series of six continuous sessions of a school enrichment program;

- a youth enrolled in subject matter clinic or special interest series;

- a youth enrolled in a summer day camp series; or a youth going to summer 4-H residential camp.
- a youth enrolled as a member of another group or after-school program while utilizing Extension curriculum for six hours or more.

4-H in Florida promotes that all youth who receive this minimum level of participation through Extension educational programs are 4-H members regardless of the method of engaging in Extension education.

This does differ from the national definition where youth in "clubs" are the only 4-H'ers referred to as "members." This difference is relevant in reports of accountability, especially for the state and federal youth statistical reports of enrollment.

\section{4-H Member Defined}

In Florida, a 4-H member is any youth, age 5-18, who enrolls and participates (individually or as part of a group) in a planned sequence of learning experiences (project) of six hours or more.

Members are guided by Extension staff or trained volunteers of both the 1862 and 1890 institutions.

\section{4-H Youth Contact Defined}

A 4-H contact is any youth taking part in a program of less than six (6) hours provided as a result of action by Extension personnel (professional, paraprofessional or volunteer). This includes youth and programs conducted through both the 1862 and 1890 institutions such as garden

\footnotetext{
${ }^{1}$ This document is 4-H S FS101.5, one of a series of the Florida 4-H Program, Florida Cooperative Extension Service, Institute of Food and Agricultural Sciences, University of Florida. This material is based upon work supported by the Cooperative Research, Education, and Extension Service, US Department of Agriculture, and K-State Research and Extension, Kansas State University, under special project number 99-EYAR-1-0747. This 4-H 101 Handbook was developed by the 4-H 101 Design Team chaired by Andrea Hutson, USDA/Army Youth Development Project, CSREES/Virginia Tech University. It was adapted for Florida by Marilyn N. Norman and Joy C. Jordan, State 4-H Program. Published May 2006. Please visit the 4-H Website at http://4h.ifas.ufl.edu/Curriculum/index.html.

${ }^{2}$ Marilyn Norman, Associate Professor in Family Youth and Community Sciences, and State 4-H Program Leader, and Joy C. Jordan, Associate Professor in Family, Youth and Community Sciences, Institute of Food and Agricultural Sciences, University of Florida, Gainesville.
} 
tours, field trips, career seminars, and similar short-term experiences.

\section{Types of Florida 4-H Member Participation}

The types of memberships or delivery methods that youth can engage in through $4-\mathrm{H}$ are summarized below. The following definitions are used for state and national statistical reporting on the youth audience of the Florida Cooperative Extension Service.

\section{4-H Organized Club Members}

Club members meet as a group on a regular schedule under the direction of an adult volunteer with a planned program

The organized 4-H club is one of the most effective delivery methods. 4 -H clubs are organized groups of boys and girls supported by adult volunteer leaders. There are different methods and locations of organizing 4-H clubs.

There are:

- multi-project or general clubs

- single project clubs

Clubs may be formed in communities, in schools, in after-school settings, and on military installations.

a. Community clubs typically meet in the evenings or on weekends and offer selfchosen multiple learning experiences and activities.

b. In-school clubs meet during school hours, have officers and planned activities beyond school enrichment.

c. 4-H after-school clubs are organized within child care settings. They have officers and planned activities.

d. Military 4-H clubs are organized by the Armed Forces, often on military installations, and principally for military dependents.

For reporting purposes, Extension 4-H does distinguish the youth enrolled in clubs at the various locations.

The 4-H club serves as the primary means of providing youth development programming in 4$\mathrm{H}$. It has the advantage of long-term involvement with the support of "caring" adults. 4-H clubs are organized and supported to provide community based positive structured learning opportunities for youth throughout their developmental years. While other 4-H delivery methods are effective, the more in-depth experiences occur in and through the club.

\section{4-H School Enrichment Members}

Youth who receive a planned sequence of learning experiences of six hours or more that involves direct teaching by Extension staff or trained volunteers, who may be teachers, in support of the school curriculum.

\section{4-H Residential/Overnight Camp Members}

Residential Camp

members are

youth who take

part in an

Extension

planned

educational

experience of group living in

the out-of-doors

that includes

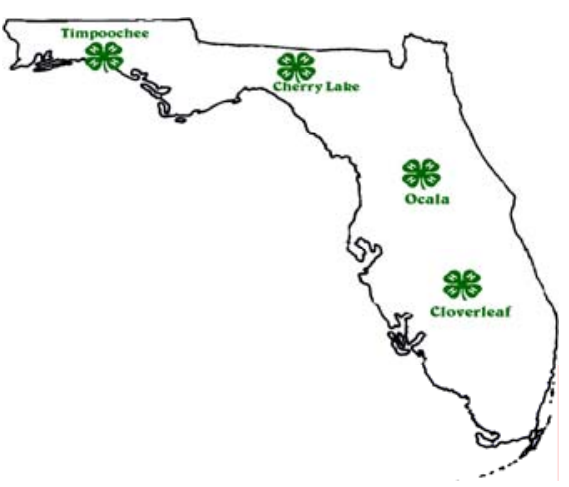

being away from home at least one night.

\section{4-H After School Members}

After school members are youth participating in a planned sequence of learning experiences outside of school hours, usually in a school or other community center and incorporating 4- $\mathrm{H}$ curricula. The primary purpose is to provide care for youth while parents are working or unavailable. (4-H clubs in school-age settings should be reported under “ Organized 4-H After School Clubs.")

\section{4-H Special Interest/Day Camp Members} Special Interest or Day Camp members are youth meeting for a specific learning experience of six hours of more that involves direct teaching by Extension staff or trained volunteers not as part of the school curriculum and not restricted to members of 4-H clubs. Day camping consists of multiple-day programs, with youth returning home each evening

\section{Individual Study/Internet Member}

An individual study member is a youth who engages in a sequence of planned learning experiences independent of any of the formal group settings or opportunities described above. This would include home study courses or Internet 
project participants (if not part of club group), usually with limited adult involvement except for parents (or project helper/mentor).

\section{Additional 4-H Events and Activities}

In addition to the learning experiences in these delivery methods to reach and teach youth, many 4-H members are provided additional structured learning opportunities through:

- Community Service projects;

- County, District or State Events, such as:

0 Competitive (Fairs, Judging etc) and

o Non-Competitive Events and Activities (Project Activities, Dances, Lock-ins);

- Leadership Experiences at the county, district or state levels, or

- Additional methods identified as appropriate for the audience reached.

4-H youth programs in any Extension program area can be designed and implemented for one or more of these youth delivery systems. For more information on existing programs opportunities and youth participation in these systems, go to the Florida 4-H website at: http://www.florida4h.org or contact your local 4-H Extension Youth agent. 